\title{
HAEMODYNAMIC EFFECTS OF UNILATERAL SPINAL ANAESTHESIA WITH LOW DOSE OF 0.5\% HYPERBARIC BUPIVACAINE- A CLINICAL STUDY
}

\author{
Yenni Shreedevi1, Gogate Vandana², C. S. Sanikop ${ }^{3}$ \\ ${ }^{1}$ Assistant Professor, Department of Anaesthesiology, Jawaharlal Nehru Medical College, Belgaum, Karnataka. \\ 2Professor, Department of Anaesthesiology, Jawaharlal Nehru Medical College, Belgaum, Karnataka. \\ 3Professor, Department of Anaesthesiology, Jawaharlal Nehru Medical College, Belgaum, Karnataka.
}

\section{ABSTRACT}

\section{BACKGROUND}

Unilateral spinal anaesthesia is a promising alternative to traditional, widely used techniques of central neuraxial blocks. Present study was taken up to assess haemodynamic effects, level achieved and duration of block with low dose $0.7 \mathrm{~mL}(3.5 \mathrm{mg})$ of $0.5 \%$ hyperbaric Bupivacaine.

\section{MATERIALS AND METHODS}

This is a one year hospital-based cross-sectional study on a total of 100 patients undergoing unilateral lower limb surgery under unilateral spinal anaesthesia. $0.7 \mathrm{~mL}(3.5 \mathrm{mg})$ of $0.5 \%$ bupivacaine heavy was injected with patient in lateral position at L3-4 space with the limb to be operated on the dependent side. Patients were maintained in lateral position for 20 minutes and then made supine. Haemodynamic parameters SBP, DBP, MBP and HR were recorded. Sensory and motor block was evaluated.

\section{RESULTS}

In this study out of 100,72 were males. Mean age was $47.79 \pm 13.91$ years and mean weight was $57.90 \pm 8.56 \mathrm{kgs}$. SBP, DBP and MBP decreased with maximum fall noted at 40 minutes and gradually increased, subsequently reaching the baseline levels at 90 minutes. Maximum increase in HR was seen at 40 minutes after giving spinal and it gradually reduced coming to baseline levels at 90 minutes. Maximum sensory level of L1 was achieved. The block remained unilateral in all the cases. Motor blockade was adequate in the limb to be operated.

\section{CONCLUSION}

Subarachnoid block with $0.7 \mathrm{~mL}(3.5 \mathrm{mg})$ of $0.5 \%$ hyperbaric bupivacaine used in this study does not produce any adverse haemodynamic changes and lasts for short duration that is 90 minutes and can be used in surgeries of shorter duration.

\section{KEY WORDS}

Very Low Dose Hyperbaric Bupivacaine; Unilateral Spinal Anaesthesia.

HOW TO CITE THIS ARTICLE: Shreedevi Y, Vandana G, Sanikop CS. Haemodynamic effects of unilateral spinal anaesthesia with low dose of $0.5 \%$ hyperbaric bupivacaine- a clinical study. J. Evolution Med. Dent. Sci. 2018;7(20)2460-2463, DOI: $10.14260 /$ jemds/2018/554

\section{BACKGROUND}

Spinal anaesthesia is commonly used in anaesthetic practice, although the undesirable sequels related to this technique are well known. In the majority of cases spinal anaesthesia is accompanied by a decrease in arterial pressure; bradycardia, due to blockage of preganglionic sympathetic fibres. The incidence of hypotension depends upon number of factors such as the extent of subarachnoid blockage, age, associated coexisting disorders, presence of medication like ßadrenergic receptor blockers etc. 1,2 Moreover, the sympathetic blockage is often accompanied by uncontrolled hypothermia, especially at low environmental temperature. ${ }^{3}$ Unilateral spinal anaesthesia is a promising alternative to traditional, widely used techniques of central neuraxial blocks as it restricts markedly the anaesthetised area, thereby decreasing the risk of adverse events and complications.

'Financial or Other Competing Interest': None.

Submission 20-03-2018, Peer Review 27-04-2018,

Acceptance 02-05-2018, Published 14-05-2018.

Corresponding Author:

Dr. Yenni Shreedevi,

Assistant Professor, Department of Anaesthesiology,

Jawaharlal Nehru Medical College,

Nehru Nagar, Belgaum-590010, Karnataka.

E-mail: shreeyenni@yahoo.co.in

DOI: $10.14260 /$ jemds $/ 2018 / 554$
Unilateral spinal anaesthesia has been used successfully in patients undergoing surgery involving one lower limb. It is particularly advantageous in high risk patients such as patients with ischaemic heart disease (IHD), congenital cardiac diseases, pulmonary diseases, diabetes where it produces less haemodynamic changes. ${ }^{4}$ It has many advantages over conventional spinal anaesthesia such as lower incidence of hypotension, faster recovery and increased patient satisfaction. ${ }^{5}$

To achieve successful unilateral anaesthesia, several factors need to be considered including site and speed of injection of anaesthetic solution, volume, baricity and concentration of the anaesthetic solution, type of needle and bevel direction as well as degree of operating table inclination. Moreover, patient posture is thought to be fundamental in determining the level of spread of anaesthesia, particularly when a hyperbaric anaesthetic solution is used. ${ }^{6}$ The dose commonly used for unilateral spinal anaesthesia is $2 \mathrm{~mL}(10 \mathrm{mg})$ of $0.5 \%$ hyperbaric Bupivacaine. The smallest dose studied is $1 \mathrm{~mL}(5 \mathrm{mg})$ of $0.5 \%$ of hyperbaric Bupivacaine. Since majority of patients requiring unilateral spinal anaesthesia have associated morbidities such as diabetes, hypertension, ischaemic heart disease, renal failure etc., anaesthetic technique which will cause no or minimal haemodynamic changes is required. In addition, the block should be adequate and should last for reasonable period of time. ${ }^{1}$ 
All earlier conducted studies ${ }^{4,5,7}$ have used 1 - $3 \mathrm{~mL}$ of $0.5 \%$ hyperbaric bupivacaine to produce unilateral anaesthesia. Increasing dosage of $0.5 \%$ hyperbaric bupivacaine is associated with increased incidence of hypotension, bradycardia and increased incidence of bilateral block which are disadvantageous in these patients.

Keeping the above scenario in mind, the present study is taken up to assess the haemodynamic effects of low dose 0.7 $\mathrm{mL}(3.5 \mathrm{mg}$ ) of $0.5 \%$ hyperbaric Bupivacaine and also to assess the level achieved and duration of block.

\section{MATERIALS AND METHODS}

The present one year hospital-based cross-sectional study was conducted during the period of January 2010 to December 2010 on 100 patients undergoing unilateral lower limb surgery under unilateral spinal anaesthesia with bupivacaine at KLES Dr. Prabhakar Kore Hospital and Medical Research Centre, Belgaum attached to Jawaharlal Nehru Medical College, Belgaum. Patients undergoing unilateral lower limb surgery with ASA Grade I and II with age more than 18 years were included in the study. The study was approved and ethical clearance was obtained from Human Ethics Committee, Jawaharlal Nehru Medical College, Belgaum and a written informed consent was obtained. Descriptive data of the patients like name, age, sex and detailed history were obtained and recorded on predesigned and pretested proforma.

Preoperatively, the patient's intravenous (IV) line was secured with either $18-\mathrm{G}$ or $20-\mathrm{G}$ branula and IV ringer lactate solution was started half an hour before spinal anaesthesia. The patient was then shifted to the operation theatre and monitors like electrocardiograph (ECG), pulse oximeter and non-invasive blood pressure monitor were connected. Preoperatively, systolic blood pressure (SBP), diastolic blood pressure (DBP), mean blood pressure (MBP) and heart rate (HR) were recorded. The patient was then placed in the lateral position with the limb to be operated placed downwards.

Under strict aseptic precautions, spinal puncture was performed at $\mathrm{L}_{3}$ - $\mathrm{L}_{4}$ interspace with 23-G Quincke's spinal needle and $0.7 \mathrm{~mL}$ of $0.5 \%$ hyperbaric bupivacaine was injected after free flow of CSF with the bevel of the needle facing towards the foot end of the patient. The drug was injected at a rate of $1 \mathrm{~mL}$ per 15 seconds. Five litres of oxygen was provided to the patient with an oxygen mask throughout the procedure. Patient was maintained in this position for 20 minutes and then placed in the supine position. The haemodynamic parameters like SBP, DBP, MBP and HR were recorded as soon as the drug was injected and at every 5 minutes interval until the completion of surgery. Sensory block was evaluated by the loss of sensation, while motor block was evaluated by Modified Bromage Scale. Sensory and motor block were evaluated in both the limbs every 10 minutes till the surgery was completed.

Hypotension was defined as $20 \%$ decrease as compared to the baseline and bradycardia was defined as heart rate less than $60 \mathrm{bpm}$. The hypotension was treated with intravenous fluids and injection Mephentermine $6 \mathrm{mg}$ bolus and bradycardia was treated with injection Atropine Sulphate 0.6 mg IV. After the patient was shifted to the recovery the haemodynamic parameters SBP, DBP, MBP, HR and the sensory and motor block were evaluated every 15 minutes until two segment regression of sensory level on the dependent side. The data was tabulated on excel spreadsheet and master chart was prepared. The data was analysed using SPSS version 20.0 statistical software. The categorical data was expressed in terms of rates, ratios and percentages and the continuous data was expressed as mean \pm standard deviation. The paired ' $t$ ' test was used to find the significance of study parameters on continuous scale.

\section{RESULTS}

In this study out of 100 patients studied, 72 (72\%) were males and 28 (28\%) were females with male-to-female ratio of 2.57: 1. Majority of the patients (45\%) were aged between 46 to 60 years followed by 30 to 45 years (28\%). Patients less than 30 years and more than 60 years were $13 \%$ and $14 \%$ respectively. Mean age among males was $48.50 \pm 14.46$ years and in females it was $46.03 \pm 12.45$ years. Overall, mean age recorded was $47.79 \pm 13.91$ years.

The mean weight among males was $59.30 \pm 8.90 \mathrm{kgs}$, whereas in females it was observed to be $54.30 \pm 6.49 \mathrm{kgs}$. The overall mean weight among the study population was $57.90 \pm 8.56$ kgs. The mean height among males was observed to be $5.60 \pm 0.61$ feet, whereas in female it was 5.40 \pm 0.21 feet. The overall height among the study population was recorded as $5.50 \pm 0.54$ feet.

The baseline SBP, DBP, MBP and HR of the patient was recorded on shifting the patient to operation theatre. Time zero was the time at which spinal anaesthesia was given. The haemodynamic parameters were recorded as soon as the drug was injected and at every 5 minutes interval until the completion of surgery.

The SBP was $123.04 \pm 8.97 \mathrm{mmHg}$ immediately after giving spinal. It showed a gradual fall with maximum fall noted at 40 minutes, the SBP being $115.72 \pm 10.38 \mathrm{mmHg}$. The SBP gradually increased, subsequently reaching the baseline levels at 90 minutes. The DBP was $77.30 \pm 4.94$ $\mathrm{mmHg}$ immediately after giving spinal. It showed a gradual fall with maximum fall noted at 40 minutes, the DBP being $72.47 \pm 7.14 \mathrm{mmHg}$. The DBP gradually increased, subsequently reaching the baseline levels at 90 minutes. The MBP was $92.54 \pm 5.98 \mathrm{mmHg}$ immediately after giving spinal. It showed a gradual fall with maximum fall noted at 40 minutes, the MBP being $87.06 \pm 7.75 \mathrm{mmHg}$. The MBP gradually increased, subsequently reaching the baseline levels at 90 minutes. The maximum increase in HR was seen at 40 minutes after giving spinal $(84.66 \pm 6.55 \mathrm{bpm})$ and it gradually reduced coming to baseline levels at 90 minutes (Graph 1).

The maximum fall in SBP, which was seen at 40 minutes following subarachnoid block was compared with SBP at time 0 using chi-square test and not found to be statistically significant $(\mathrm{p}=0.960)$. The maximum fall in DBP was also seen at 40 minutes following subarachnoid block and was compared with DBP at time 0 using chi-square test and not found to be statistically significant $(p=0.724)$. The maximum fall in MBP was seen at 40 minutes following subarachnoid block and was compared with MBP at time 0 using chi-square test and not found to be statistically significant $(\mathrm{p}=0.861)$ The maximum change in HR was seen at 40 minutes following subarachnoid block and was compared with HR at time 0 using chi-square test and not found to be statistically significant $(\mathrm{p}=0.936)$ (Table 1$)$. 


\begin{tabular}{|c|c|c|c|c|c|}
\hline & \multicolumn{2}{|c|}{ 0 Minutes } & \multicolumn{2}{c|}{$\begin{array}{c}\text { Time of } \\
\text { Maximum } \\
\text { Change } \\
\text { (40 Minutes) }\end{array}$} & \multirow{2}{*}{ 'p' value } \\
& \multicolumn{2}{|c|}{} & \multicolumn{2}{|c|}{} \\
\cline { 2 - 5 } & Mean & S.D. & Mean & S.D. & \\
\hline SBP (mmHg) & 123.04 & 8.97 & 115.72 & 10.38 & 0.960 \\
\hline DBP (mmHg) & 77.30 & 4.94 & 72.47 & 7.14 & 0.724 \\
\hline MBP (mmHg) & 92.54 & 5.98 & 87.06 & 7.75 & 0.861 \\
\hline HR (/Min) & 82.64 & 5.95 & 84.66 & 6.55 & 0.936 \\
\hline
\end{tabular}

Table 1. Mean Change in Haemodynamic Parameters

\begin{tabular}{|c|c|c|c|c|}
\hline \multirow{2}{*}{ Block Levels } & \multicolumn{2}{|c|}{ At 15 minutes } & \multicolumn{2}{c|}{ At 20 minutes } \\
\cline { 2 - 5 } & Number & Percentage & Number & Percentage \\
\hline L1 & 82 & $82 \%$ & 100 & $100 \%$ \\
\hline L2 & 18 & $18 \%$ & 00 & $00 \%$ \\
\hline \multicolumn{4}{|c}{ Table 2. Levels of Sensory Block } \\
\hline
\end{tabular}

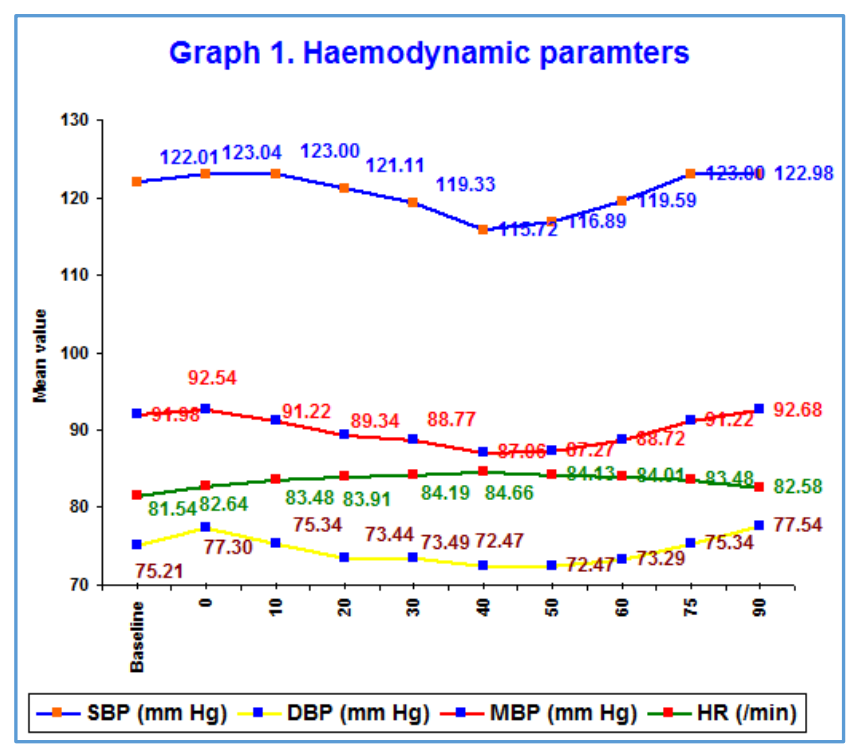

\section{DISCUSSION}

Unilateral spinal anaesthesia is a promising alternative to traditional, widely used techniques of central blocks, as it restricts markedly the anaesthetised area, thereby decreases the risk of adverse events and complications. ${ }^{3}$

In our study, we have used $0.5 \%$ hyperbaric bupivacaine as unilateral block can be produced reliably with hyperbaric solutions. With isobaric or hypobaric solutions, the incidence of bilateral block has been shown to be higher.

In this study, gender distribution showed male preponderance with $72 \%$ males and $28 \%$ females. The maleto-female ratio was 2.57: 1 . Most of the patients (45\%) were aged between 46 to 60 years followed by 30 to 45 years (28\%). However, patients between less than 30 years and more than 60 years were $13 \%$ and $14 \%$ respectively. Mean age among males was $48.50 \pm 14.46$ years and in females it was $46.03 \pm 12.45$ years. Overall, mean age recorded was $47.79 \pm 13.91$ years. It is considered that duration of spinal anaesthesia increases with age. The time to onset of analgesia and maximal motor blockade have been found to decrease with age. Recovery time from sensory block is prolonged in the older patients. The rate of two segment regression is not affected. ${ }^{8}$ In our study however we did not find any significant difference in characteristics of sensory and motor block.

In this study the mean weight among males was $59.30 \pm$ $8.90 \mathrm{kgs}$, whereas in females it was observed to be $54.30 \pm$
6.49 kgs. The overall mean weight among the study population was $57.90 \pm 8.56 \mathrm{kgs}$. With the standardised technique of spinal anaesthesia, it is usual for higher level anaesthesia to occur in obese patients, especially when they are overweight by $40 \%$ to $50 \%$ or more. None of the patients in our study were obese. 8

The mean height among males was observed to be $5.60 \pm 0.61$ feet, whereas in female it was $5.40 \pm 0.21$ feet. The overall height among the study population was recorded as $5.50 \pm 0.54$ feet. Height has negative effect on the level of blockade for a given weight, that is tall patients with standardised spinal technique had lower levels of analgesia than the patients with short stature. All the patients in our study were comparable in height. ${ }^{8}$

Hyperbaric solutions are readily controlled after SAB by proper positioning of the patient. Generally, hyperbaric solution tends to travel to the most dependent part of subarachnoid space.

The optimum time for maintaining the patient in lateral position and thereby producing a unilateral block is controversial. With high doses of hyperbaric bupivacaine (12.5 $\mathrm{mg}$ and $15 \mathrm{mg}$ ), there is high incidence of bilateral block even when patient remains in lateral position for 30 minutes to 1 hour.9,10 Conversely, with low doses of hyperbaric bupivacaine, motor block remains unilateral even when patient is made supine after 10 to 15 minutes in lateral position. ${ }^{11,12,13}$

In our study, we kept the patient in lateral position for 20 minutes following $3.5 \mathrm{mg}$ of intrathecal hyperbaric bupivacaine. This resulted in successful unilateral block in $100 \%$ of the patients. There was no anaesthetic migration leading to bilateral block.

The mean SBP at induction was $122.01 \pm 8.07 \mathrm{mmHg}$ and immediately after giving spinal was $123.04 \pm 8.97 \mathrm{mmHg}$. Maximum fall was noted at 40 minutes, which was $115.72 \pm$ $10.38 \mathrm{mmHg}$. The mean DBP at induction was $75.21 \pm 4.98$ $\mathrm{mmHg}$ and immediately after giving spinal was $77.30 \pm 4.94$ mmHg. Maximum fall was noted at 40 minutes, which was $72.47 \pm 7.14 \mathrm{mmHg}$. The mean MBP at induction was $91.98 \pm$ $5.92 \mathrm{mmHg}$ and immediately after giving spinal was $92.54 \pm$ $5.98 \mathrm{mmHg}$. Maximum fall was noted at 40 minutes, which was $87.06 \pm 7.75 \mathrm{mmHg}$. The mean HR at induction was $81.54 \pm 5.86 \mathrm{mmHg}$ and immediately after giving spinal was $82.64 \pm 5.95 \mathrm{mmHg}$. Maximum rise was noted at 30 minutes, which was $85.49 \pm 7.25 \mathrm{mmHg}$. When compared statistically the reduction in SBP, DBP, MBP and increase in HR was not found to be statistically significant.

In a study 5 from Regional Hospital, Myslowice to assess unilateral spinal anaesthesia and to verify the hypothesis about safety-related superiority of this technique over bilateral anaesthesia in patients undergoing unilateral subarachnoid blockage with hyperbaric $0.5 \%$ bupivacaine, the decrease in mean MAP at $5^{\text {th }}$ and $16^{\text {th }}$ mins of anaesthesia was 13.3 and $17.5 \mathrm{mmHg}$, respectively. The comparative assessment of both techniques of administration of $0.5 \%$ bupivacaine in the lateral decubitus position did not show differences between the fast and conventional injection: changes in MAP ranged from $1.8 \mathrm{mmHg}$ to $4.2 \mathrm{mmHg} .{ }^{14}$ Our findings are similar, yet the rate of local anaesthetic injection was the same in all patients. The study concluded that unilateral spinal anaesthesia is safe, especially when the dose of bupivacaine is lower and haemodynamic stability is better. 
Our results are comparable with a study from Karachi done to assess whether a unilateral spinal anaesthesia using $0.5 \%$ hyperbaric Bupivacaine will restrict the sympathetic block to avoid the undesired cardiovascular effects. The study reported that unilateral spinal anaesthesia is very effective in restricting the sympathetic block, as all high risk patients showed minimal haemodynamic changes following the technique.

A review of clinical studies ${ }^{15}$ on this topic trying to outline the feasibility and potential clinical benefits of unilateral spinal anaesthesia including the main results of studies recently published in peer reviewed journals concerning the clinical use of unilateral spinal anaesthesia reported that the main factors to be considered when attempting a unilateral spinal block are the use of small doses of local anaesthetic solution injected through directional, pencil-point needles, together with a 15 - 20 mins lateral decubitus position and the use of either hypo- or hyperbaric anaesthetic solution. Using 6 - $8 \mathrm{mg}$ of either hyper- or hypobaric bupivacaine provides a unilateral distribution of sympathetic and sensory blocks in 50 to $70 \%$ of patients, while unilateral motor block can be observed in up to $80 \%$ of cases.

Another prospective, randomised, parallel group study 3 from Milan to evaluate cardiac performance during unilateral subarachnoid block and to compare it with that produced by standard bilateral spinal anaesthesia reported that the use of restricted to the operative side with minimal effects on cardiovascular homeostasis. $8 \mathrm{mg}$ of $0.5 \%$ hyperbaric bupivacaine slowly injected through a directional needle provided a spinal block relatively

Attempting a unilateral spinal block results in a four-fold reduction in the incidence of clinically relevant hypotension with more stable cardiovascular parameters as compared with conventional bilateral spinal block. The small amount of local anaesthetic solution injected as well as the reduced extent of spinal block also provide a favourable profile of the resolution of spinal block, which can be useful in the ambulatory setting. With simple technical skill we can reliably provide a preferential distribution of spinal block to the operated side. This results in a minimal delay in preparation time, but provides less haemodynamic side effects with higher cardiovascular stability and increased autonomy after surgery with better patient acceptance.

However, with this small dose of drug, block lasted for short duration (90 minutes) and can be used only in surgeries of shorter duration which is a limitation. In view of short duration of motor blockade, the use of this dose of hyperbaric bupivacaine for day care surgeries can be evaluated. Also as this small dose causes minimal haemodynamic changes, it can be used judiciously in ASA grade III and IV patients. A study ${ }^{1}$ using 1.1 to $1.8 \mathrm{~mL}$ of $0.5 \%$ hyperbaric bupivacaine reported that unilateral spinal anaesthesia is very effective and also showed that there were minimal haemodynamic changes following the technique in ASA grade III and IV patients. Hence, effect of this small dose that is $0.7 \mathrm{~mL}(3.5 \mathrm{mg})$ in ASA grade III and IV may be studied.

\section{CONCLUSION}

Overall, in the present study there was no significant change in SBP, DBP, MBP and HR and the block remained unilateral with adequate sensory level of L1 was achieved and block lasted for 70 to 100 minutes.

\section{REFERENCES}

[1] Casati A, Fanelli G, Beccaria P, et al. Block distribution and cardiovascular effects of unilateral spinal anaesthesiology by $0.5 \%$ hyperbaric bupivacaine. A clinical comparison with bilateral spinal block. Minerva Anesthesiol 1998;64(7-8):307-12.

[2] Veering BT, Immink-Speet TT, Burm AG, et al. Spinal anaesthesia with $0.5 \%$ hyperbaric bupivacaine in elderly patients: effects of duration spent in the sitting position. Br J Anaesth 2001;87(5):738-42.

[3] Karpel E, Marszołek P, Pawlak B, et al. Effectiveness and safety of unilateral spinal anaesthesia. Anestezjol Intens Ter 2009;41(1):33-6.

[4] Chohan U, Afshan G, Hoda MQ, et al. Haemodynamic effects of unilateral spinal anaesthesia in high risk patients. J Pak Med Assoc 2002;52(2):66-9.

[5] Imbelloni LE, Beato L, Cordeiro JA. Unilateral spinal anaesthesia with low 0.5\% hyperbaric bupivacaine dose. Rev Bras Anestesiol 2004;54(5):700-6.

[6] Gouveia MA. Fatores que Controlam a Dispersão das Drogas na Raquianestesia, em: Imbelloni LE - Tratado de Anestesia Raquidiana, Curitiba 2001;7:67-73.

[7] Liu SS, Ware PD, Allen HW, et al. Dose-response characteristics of spinal bupivacaine in volunteers. Clinical implications for ambulatory anesthesia. Anesthesiology 1996;85(4):729-36.

[8] Collins VJ. Principles of anaesthesiology general and regional. Vol. 2. $3^{\text {rd }}$ edn. Pennsylvania: Lee and Febiger 1993.

[9] Lotz SMN, Crosgnac M, Katayama M, et al. Anestesia subaracnóidea com bupivacaína a 0, 5\% hiperbárica: influência do tempo de permanência em decúbito lateral sobre a dispersão cefálica. Rev Bras Anestesiol 1992;42:257-64.

[10] Povey HM, Jacobsen J, Westergaard-Nielsen J. Subarachnoid analgesia with hyperbaric $0.5 \%$ bupivacaine: effect of a 60-minutes period of sitting. Acta Anaesthestiol Scand 1989;33(4):295-7.

[11] Casati A, Fanelli G, Cappelleri G, et al. Low dose hyperbaric bupivacaine for unilateral spinal anaesthesia. Can J Anaest 1998;45(9):850-4.

[12] Pittoni G, Toffoletto F, Calcarella G, et al. Spinal anesthesia in outpatient knee surgery: 22-gauge versus 25-gauge Sprotte needle. Anesth Analg 1995;81(1):73-9.

[13] Kuusniemi KS, Pihlajamaki KK, Pitkanen MT. A low dose of plain or hyperbaric bupivacaine for unilateral spinal anesthesia. Reg Anesth Pain Med 2000;25(6):605-10.

[14] Enk D, Prien T, Van Aken H, et al. Success rate of unilateral spinal anaesthesia is dependent on injection flow. Reg Anesth Pain Med 2001;26(5):420-7.

[15] Casati A, Fanelli G. Unilateral spinal anesthesia. State of the art. Minerva Anestesiol 2001;67(12):855-62. 